See Article page 972.

\section{Commentary: Acute type A dissection and sex: A matter of biology or of imperfect adjustment?}

\author{
N. Bryce Robinson, MD, and \\ Mario Gaudino, MD, PhD, MSCE
}

Generally women are at increased risk of major morbidity and mortality following cardiac surgery compared with men. In fact, previous reports have identified female sex as an independent risk factor for mortality following coronary artery bypass grafting despite adjustment for multiple risk factors. ${ }^{1}$ This can be explained in part by the fact that women are older at presentation and have higher rates of important medical comorbidities, such as hypertension, diabetes, peripheral artery disease, and congestive heart failure at presentation. ${ }^{2}$ Furthermore, women have smaller coronary artery diameters compared with males, irrespective of body size. ${ }^{3}$ Similar intrinsic differences have been described for mitral valve repair and replacement, but the evidence related to sex-specific outcomes following acute type A aortic dissection (ATAAD) remains sparse.

In this issue of the Journal, Norton and colleagues ${ }^{4}$ investigate the impact of female sex on outcomes following operative repair of ATAAD in 650 patients, of whom $206(32 \%)$ were women. The authors found that compared with men, women were significantly older and had higher rates of hypertension and stroke at presentation but less extensive dissections and a lower rate of root replacement. Operative mortality was significantly lower for women compared with men, with male sex identified as an independent

From the Department of Cardiothoracic Surgery, Weill Cornell Medicine, New York, NY.

Disclosures: The authors reported no conflicts of interest.

The Journal policy requires editors and reviewers to disclose conflicts of interest and to decline handling or reviewing manuscripts for which they may have a conflict of interest. The editors and reviewers of this article have no conflicts of interest.

Received for publication April 1, 2021; revisions received April 1, 2021; accepted for publication April 5, 2021; available ahead of print April 12, 2021.

Address for reprints: Mario Gaudino, MD, PhD, MSCE, Department of Cardiothoracic Surgery, Weill Cornell Medicine, 525 E 68th St, New York, NY 10065 (E-mail: mfg9004@med.cornell.edu).

J Thorac Cardiovasc Surg 2023;165:982-3

$0022-5223 / \$ 36.00$

Copyright (c) 2021 by The American Association for Thoracic Surgery

https://doi.org/10.1016/j.jtcvs.2021.04.005

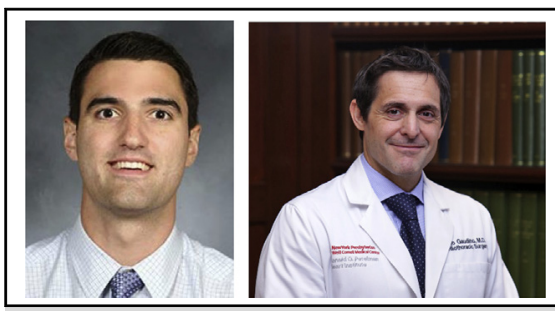

N. Bryce Robinson, MD, and Mario Gaudino, MD, PhD, MSCE

\section{CENTRAL MESSAGE}

The impact of female sex on

outcomes following acute type A aortic dissection remains unclear.

predictor of mortality. Notably, 10-year survival was similar in the two groups.

The authors are to be commended for this series, with an overall operative mortality rate of $8.0 \%$. Like all analyses, however, this study should be interpreted in the context of some important limitations. As the authors acknowledge, this is a single-center retrospective series with specialized aortic surgeons, and caution should be taken when extrapolating results to all patients and institutions. In fact, a large analysis from the International Registry of Acute Aortic Dissection found that women had higher rates of operative mortality following repair of ATAAD, even after adjusting for age and hypertension-findings contrary to those of the present smaller, single-center analysis. ${ }^{5}$

Most importantly, male and female patients present with intrinsic differences. In this analysis, although women had significantly higher rates of hypertension and stroke at presentation, they had lower rates of end-organ malperfusion, less renal failure, and better baseline left ventricular function. Furthermore, male patients had more extensive dissections and underwent more complex operations, as reflected by higher rates of root replacement and significantly longer cardiopulmonary bypass and cross-clamp times, known risk factors for increased mortality following ATAAD. Observational series are known to be limited by unmeasured confounders, even when complex matching techniques are used to minimize differences between patient populations. ${ }^{6}$ These intrinsic baseline differences in the patient populations, rather than biological sex alone, may explain any difference in operative mortality observed.

To be sure, this analysis attempts to address an important question in the ever-evolving surgical treatment of ATAAD. However, the question of whether sex has an impact on outcomes remains unclear. Future analyses should focus 
specifically on women to improve perioperative care following ATAAD.

\section{References}

1. Blankstein R, Ward RP, Arnsdorf M, Jones B, Lou YB, Pine M. Female gender is an independent predictor of operative mortality after coronary artery bypass graft surgery: contemporary analysis of 31 Midwestern hospitals. Circulation. 2005; 112(9 Suppl):I323-7.

2. Ahmed WA, Tully PJ, Knight JL, Baker RA. Female sex as an independent predictor of morbidity and survival after isolated coronary artery bypass grafting. Ann Thorac Surg. 2011;92:59-67.
3. Sheifer SE, Canos MR, Weinfurt KP, Arora UK, Mendelsohn FO, Gersh BJ, et al Sex differences in coronary artery size assessed by intravascular ultrasound. Am Heart J. 2000;139:649-53.

4. Norton EL, Kim KM, Fukuhara S, Wu X, Patel HJ, Deeb GM, et al. Differences among sexes in presentation and outcomes in acute type A aortic dissection repair. J Thorac Cardiovasc Surg. 2023;165:982-3.

5. Nienaber CA, Fattori R, Mehta RH, Richartz BM, Evangelista A, Petzsch M, et al Gender-related differences in acute aortic dissection. Circulation. 2004;109: 3014-21.

6. Gaudino M, Di Franco A, Rahouma M, Tam DY, Iannaccone M, Deb S, et al. Unmeasured confounders in observational studies comparing bilateral versus single internal thoracic artery for coronary artery bypass grafting: a meta-analysis. $J$ Am Heart Assoc. 2018;7:e008010. 